\title{
Erratum to: FDA proposals to limit the hepatotoxicity of paracetamol (acetaminophen): are they reasonable?
}

\author{
Garry G. Graham • Richard O. Day • \\ Andis Graudins • Anthoulla Mohamudally
}

Published online: 10 April 2010

(C) Springer Basel AG 2010

\section{Erratum to: Inflammopharmacol}

\section{DOI 10.1007/s10787-010-0036-6}

The original version of this article unfortunately contains a mistake. The article category is wrong. The correct article category should be a "Commentary".

The online version of the original article can be found under doi:10.1007/s10787-010-0036-6.

G. G. Graham $(\bowtie)$ - R. O. Day

Department of Clinical Pharmacology, St Vincent's Hospital,

Darlinghurst, NSW 2010, Australia

e-mail: g.graham@unsw.edu.au

G. G. Graham

Department of Pharmacology, School of Medical Sciences,

University of NSW, Sydney, Australia

G. G. Graham

St Vincent's Hospital Clinical School, University of New South

Wales, Sydney, Australia

A. Graudins

Emergency Medicine Research and Clinical Toxicology,

Monash Medical Centre and Southern Clinical School,

Monash University, Melbourne, Australia

A. Mohamudally

Cunningham Centre for Palliative Care, St Vincent's Hospital,

Sydney, Australia 